\title{
Study of Antirestenosis With the BiodivYsio Dexamethasone-Eluting Stent (STRIDE): A First-in-Human Multicenter Pilot Trial
}

\author{
Xiaoshun Liu, ${ }^{1}$ MD, Yanming Huang, ${ }^{1}$ MD, Claude Hanet, ${ }^{2}$ MD, Michel Vandormael, ${ }^{3}$ MD, \\ Victor Legrand, ${ }^{4}$ MD, Joseph Dens, ${ }^{1}$ MD, Jean Luc Vandenbossche, ${ }^{5}$ MD, Luc Missault, ${ }^{6}$ MD, \\ Christiaan Vrints, ${ }^{7} \mathrm{MD}$, and Ivan De Scheerder, ${ }^{1 *} \mathrm{MD}, \mathrm{PhD}$
}

\begin{abstract}
The aim of this multicenter pilot study was to evaluate the acute safety and efficacy of the dexamethasone-eluting stent $\left(0.5 \mu \mathrm{g} / \mathrm{mm}^{2}\right.$ of stent) implanted in patients with de novo single-vessel disease. This study included 71 patients, $42 \%$ of whom had unstable angina pectoris. An appropriately sized BiodivYsio Matrix Lo stent loaded with a total dexamethasone dose of $0.5 \mu \mathrm{g} / \mathrm{mm}^{2}$ of stent was used. Technical device success rate was $95 \%$. Six-month MACE occurred in two patients (3.3\%). Binary restenosis rate was $13.3 \%$. Late loss was 0.45 . Late loss and percent diameter stenosis were lower in the unstable angina pectoris patients compared to the stable patients $(0.32 \pm 0.39$ vs. $0.60 \pm 0.55 \mathrm{~mm}, P<$ 0.07 , and $26.86 \pm 14$ vs. $38.40 \pm 16 \%, P<0.02$ ). This study demonstrated the feasibility and safety of the implantation of a dexamethasone-eluting stent and its effect on in-stent neointimal hyperplasia. Catheter Cardiovasc Interv 2003;60:172-178.

$\odot 2003$ Wiley-Liss, Inc.
\end{abstract}

Key words: drug-eluting stent; dexamethasone

\section{INTRODUCTION}

In-stent restenosis, mainly caused by an abundant neointimal hyperplasia, remains the major limitation of coronary stent implantation. Mural thrombi, inflammatory response, smooth muscle cell (SMC) dedifferentiation, migration, and proliferation, and extracellular matrix formation all participate to the pathogenesis of neointimal hyperplasia. Changing any of these factors might have an impact on neointimal hyperplasia. Systemic delivery of medications has been unsuccessful in reducing restenosis. Local drug delivery via infusion devices introduced additional complexity to the procedure and may not deliver sufficient medication to the site of the injury. It also resulted in insufficient results. Drug-eluting stents, however, can deliver an adequate amount of medication to the site of injury for a sufficient period of time and have been proposed as an alternative approach to decrease neointimal hyperplasia. Some preliminary studies have shown very promising results [1,2].

Dexamethasone is a generic anti-inflammatory compound approved by the FDA over 30 years ago and is widely used. Dexamethasone is a glucocorticoid, which readily crosses cell membranes and binds to specific cytoplasmic receptors, resulting in the modification of protein synthesis, thereby inhibiting inflammatory responses. Continuous administration of hydrocortisone or dexamethasone, either systemically or from periadventitial polymers, has been shown to reduce reactive intimal hyperplasia in rabbit and rat models of restenosis $[3,4]$. Local drug delivery of dexamethasone from a poly-Llactic acid-coated stent in a porcine model did not result in a reduction of intimal hyperplasia [5]. However, it has been shown that biodegradable polymers can cause increased inflammation and neointimal thickening in a porcine model [6].

\footnotetext{
${ }^{1}$ Department of Cardiology, University Hospitals Leuven, Leuven, Belgium

${ }^{2}$ Department of Cardiology, UCL St. Luc, Brussels, Belgium ${ }^{3}$ Department of Cardiology, CG St. Jean, Brussels, Brussels, Belgium

${ }^{4}$ Department of Cardiology, CHU Sart Tilman, Liege, Belgium ${ }^{5}$ Department of Cardiology, CHU St. Pierre, Brussels, Belgium ${ }^{6}$ Department of Cardiology, AZ St. Jan Brugge, Brugge, Belgium

${ }^{7}$ Department of Cardiology, UZ Antwerp, Belgium
}

\begin{abstract}
*Correspondence to: Dr. Ivan De Scheerder, Department Of Cardiology, University Hospital Gasthuisberg, Herestraat 49, B-3000 Leuven, Belgium. E-mail: ivan.descheerder@med.kuleuven.ac.be
\end{abstract}

Received 20 August 2002; Revision accepted 9 June 2003

DOI 10.1002/ccd.10636

Published online in Wiley InterScience (www.interscience.wiley.com). 
Preclinical studies, using the BiodivYsio drug delivery phosphorylcholine stent, which has been shown to cause no inflammatory reaction [7-10], loaded with a high dose of dexamethasone have shown a decreased neointimal hyperplasia [11] in a porcine coronary model.

The aim of this study was to evaluate the safety and efficacy of the BiodivYsio Matrix Lo stent loaded with dexamethasone. The primary objective was to evaluate the proportion of patients having an angiographic restenosis 6 months after receiving the BiodivYsio Matrix Lo stent loaded with dexamethasone. The secondary objectives were to evaluate the safety and the 6-month quantitative coronary angiographic endpoints after receiving the BiodivYsio Matrix Lo stent loaded with dexamethasone.

\section{MATERIALS AND METHODS}

\section{Dxamethasone-Loaded BiodivYsio Matrix Lo Stent}

The BiodivYsio Matrix Lo stent system consists of a stainless steel stent coated with a phosphorylcholine (PC) polymer. It has the ability to absorb and release therapeutic agents, providing an inert depot for controlled local drug release [12]. Once loaded, the release of the therapeutic agent from the coating takes place in a controlled and sustained manner [13]. Therefore, when the stent is placed in contact with the vessel wall, release of the therapeutic agent is confined to the desired target providing high local drug concentrations. Loading studies using dexamethasone have shown that after an immersion time of approximately 5 min there is little or no increase in the amount of drug absorbed onto the BiodivYsio Matrix Lo stent. On contact with the solvent, the PC coating swells, allowing the drug to be absorbed into the coating [14]. This process occurs immediately after the PC coating comes in contact with the drug solution. The amount of drug absorbed into the coating is dependent on the concentration of the drug solution and the volume of coating on a stent. Release of the absorbed therapeutic agents occurs by passive diffusion out of the PC coating.

In vitro drug release studies using a $5 \mathrm{ml}$ phosphate buffer solution at $25^{\circ} \mathrm{C}$ have shown that formulated dexamethasone (molecular weight, 392.5; Gensia; $10 \mathrm{mg} / \mathrm{ml}$ in isotonic solution) exhibited a fast in vitro release: $95 \%$ of the drug was released in $25 \mathrm{~min}$, and the total amount of drug was released within $2 \mathrm{hr}$. A bulk-loaded dexamethasone $(15 \mathrm{mg} / \mathrm{ml}$ in EtOH sparingly solution) was released within $20 \mathrm{hr}$. The latter drug concentration and 11, 15, and $18 \mathrm{~mm}$ long BiodivYsio Matrix Lo stents with a diameter of $3.0,3.5$, or 4.0 were used in this trial.

\section{Patient Population}

This multicenter prospective trial was performed at eight interventional cardiovascular centers in Belgium. Seventy symptomatic patients with documented myocardial ischemia (stable or unstable angina pectoris, or positive exercise test) with de novo coronary lesions were included in this study. All patients were required to agree to a 6-month clinical and angiographic follow-up and had to be over 21 years old. The reference vessel diameter of the treated lesion was visually estimated to be $>2.75$ $\mathrm{mm}$ and $<4.0 \mathrm{~mm}$ in diameter; target lesion stenosis was $>50 \%$ and $<100 \%$. Noncalcified lesions, $<15 \mathrm{~mm}$ long, requiring one appropriately sized 11,15 , or $18 \mathrm{~mm}$ BiodivYsio Matrix Lo stent were included.

The following patient categories were excluded from the study: patients with ostial and bifurcation lesions, left ventricular ejection fraction $<30 \%$, recent acute myocardial infarction (within $72 \mathrm{hr}$ of the intended treatment), history of cerebrovascular accident (CVA) or transitory ischemic attack (TIA) in previous 3 months, known hypersensitivity or contraindication to aspirin or stainless steel, or a sensitivity to contrast dye, allergy to heparin or ticlopidine, active peptic ulcer or upper gastrointestinal bleeding, renal failure, liver disease, or diabetes mellitus. The following patients who in the opinion of the investigator could compromise the ability to participate in this trial were also excluded: pregnant women or those of child-bearing potential, those with a concurrent medical condition with a life expectancy of less than 12 months, or those under any medical or psychiatric conditions.

The ethics committee at each center approved the protocol. The consent form or modification based on local independent ethics committee recommendations was completed by all enrolled subjects and signed by the operating physician.

\section{Procedure}

All patients were premedicated with acetyl salicylic acid (ASA; $160 \mathrm{mg} / \mathrm{d}$ ) orally. Oral ticlopidine $500 \mathrm{mg}$ was given before PTCA. Standard balloon angioplasty was performed via the femoral approach. Heparin (100 $\mathrm{U} / \mathrm{kg}$ ) after insertion of the arterial sheath was weightadjusted and administered as needed to maintain an activated clotting time (ACT) of approximately 250-300 sec. Intracoronary nitroglycerin $100-200 \mu \mathrm{g}$ was administered immediately prior to baseline angiography, poststent deployment, and after final postdilatation angiography.

Initial angiograms were performed in two orthogonal projections or, if not possible, in two different nonorthogonal views perpendicular to the investigated arte- 
rial segment. Under the same angiographic conditions, the same projections were repeated during the follow-up studies.

After predilatation, angiography was performed and evaluated. A premounted, appropriately sized BiodivYsio Matrix Lo stent was selected and immersed in a solution of $15 \mathrm{mg} / \mathrm{ml}$ dexamethasone, yielding a total dexamethasone dose of $0.5 \mu \mathrm{g} / \mathrm{mm}^{2}$ of stent. The stent and delivery balloon were allowed to rest in the sterile solution for a minimum of $5 \mathrm{~min}$ and then were left to air-dry in the sterile field for 5 min. After that time, the dexamethasone-loaded BiodivYsio Matrix Lo stent was deployed at the treatment site. The prepared stent delivery system was advanced over the guidewire through the guiding catheter to the targeted lesion site. The stent was positioned across the lesion and placement was confirmed with fluoroscopic test injections.

After removal of the balloon catheter, contrast was injected to assess the final angiographic result. In case of a suboptimal stent apposition, additional high pressure or upsized balloon inflations were performed.

Procedural success was defined as a $20 \%$ reduction in diameter stenosis (DS) and less than 50\% residual stenosis stent implantation. After stent implantation, aspirin was continued indefinitely and ticlopidine $(250 \mathrm{mg} / \mathrm{d})$ was prescribed for 28 days in all cases.

\section{Quantitative Coronary Angiographic Analysis}

Preprocedural, post-PTCA, poststent, and 6-month follow-up quantitative coronary angiographic measurements were performed offline by a specially trained investigator who was not involved in the angioplasty procedure. Quantitative coronary angiographic analysis was performed using a computer-assisted automated arterial contour detection system (AWOS version 4.01, Siemens, Erlangen, Germany), which has been validated in vitro and in vivo. Each lesion was analyzed in two approximately orthogonal projections selected for maximally avoiding superimposition and vessel foreshortening. The distal end of the guiding catheter was used for calibration in each analyzed projection. The in-lesion segment was defined as the stent plus $5 \mathrm{~mm}$ proximal and $5 \mathrm{~mm}$ distal to the edge or the nearest side branch. In-stent and in-lesion restenosis were defined as $>50 \%$ DS at follow-up, located within the stent and target lesion, respectively. Reference and minimal luminal diameter (MLD), as well as the degree of percentage diameter stenosis before and after angioplasty, after stent implantation, and at 6-month follow-up were studied. All measurements were assessed in both obtained views and averaged. Acute gain, late loss, and net gain were subsequently calculated. Acute gain was defined as the difference between the post- and preprocedural MLD, while late loss and net gain were calculated by subtracting the
MLD at follow-up from the postprocedural and preprocedural MLD, respectively [15].

\section{Clinical Follow-Up}

All patients were asked to return to the investigative site or their primary cardiologist for a clinical visit 4 weeks postprocedure to monitor acute clinical events. All patients were contacted by telephone by the investigative site at 3 months \pm 1 week for a safety evaluation. All subjects were required to return to the investigative site for a repeat coronary angiography whether they were experiencing symptoms or not. If a patient had a positive exercise stress test at any time up to and including his required follow-up, a repeat angiogram was performed.

\section{Definitions, Study Endpoints, and Statistics}

Intention-to-treat population was defined as all patients who received the dexamethasone-eluting stent. Per-protocol population was defined as all patients in the intention-to-treat population who did not deviate from the protocol. The patients with unstable angina were classified according to the Braunwald classification. Stable angina was defined according to the Canadian Cardiovascular Society (CCS) classification. The unstable group included patients with unstable angina (new onset or changed pattern of angina over the previous 2 months) and CCS class IV angina at presentation. The stable group included patients with stable angina (CCS class I, II, or III angina unchanged over $\geq 2$ months) or patients with a positive stress test. The primary endpoint was angiographic restenosis. The secondary endpoints were 30-day and 6-month major adverse cardiac events (death, myocardial infarction, or clinically driven target lesion revascularization). Quantitative coronary angiographic endpoints included late loss, loss index, and late MLD at 6-month control angiography.

Categorical variables were summarized using counts and percentages. Continuous variables were summarized using mean, standard deviation, minimum, maximum, and median for variable not showing a normal distribution. For comparison of subgroups, the unpaired twotailed Student's $t$-test was used. Results were considered statistically significant at $P<0.05$.

\section{RESULTS}

From 16 January to 5 June 2001, 71 patients from eight study sites were included. Table I represents the baseline clinical characteristics of the study population. The mean age was 61.9 with a range from 36 to 82 years. Twenty-one percent were females. Sixty-eight percent of the patients had hypercholesterolemia, 56\% had hypertension, $45 \%$ had a previous MI, $42 \%$ had unstable 
TABLE I. Baseline Clinical Characteristics*

\begin{tabular}{lc}
\hline & $\mathrm{n}(\%)$ \\
\hline Study population & 71 \\
Female/male & $15 / 56(21 / 79)$ \\
Mean age (years) & $61.9($ range, $36 / 82)$ \\
Family history CHD & $24(34)$ \\
Hypercholesterolaemia & $48(68)$ \\
Hypertension & $40(56)$ \\
Peripheral vascular disease & $5(7)$ \\
Previous stroke & $5(7)$ \\
Previous MI & $32(45)$ \\
Previous PTCA & $11(15)$ \\
Never smoked & $16(23)$ \\
Current smokers & $24(34)$ \\
Ex-smokers & $25(25)$ \\
Not known & $6(8)$ \\
Stable angina & $27(38)$ \\
Unstable angina & $30(42)$ \\
Silent ischemia & $14(20)$ \\
\hline
\end{tabular}

CHD, coronary heart disease.

*Values are mean $\pm \mathrm{SD}$ or $\mathrm{n}(\%)$.

angina pectoris. Eleven patients were excluded from the per-protocol analysis as they violated inclusion and/or exclusion criteria. In three patients the target vessel reference diameter was $<2.75 \mathrm{~mm}$; two patients were excluded because they were diabetic; in one patient the study stent was used to treat a type F dissection after balloon angioplasty; in one patient the study stent covered a $>2 \mathrm{~mm}$ side branch; two patient were excluded because of recent myocardial infarction; one patient with triple-vessel disease was excluded because of planned staged procedure; and finally one patient was excluded because the target lesion was longer than $15 \mathrm{~mm}$.

\section{In-Hospital Results, 30-Day and 6-Month Major Adverse Coronary Events}

Technical device success (defined as study stent successfully implanted as first stent) was achieved in $95 \%$ of patients; there were no procedural MACE recorded. One patient in whom the balloon angioplasty was complicated by a long $(>30 \mathrm{~mm})$ type $\mathrm{F}$ dissection, treated with a single study stent, died during the hospital stay due to a cardiac arrest following attempts to cannulate a central vein. All other patients were discharged without complications $24 \mathrm{hr}$ after stent implantation. During the 30-day follow-up, one patient developed a non-Q-wave myocardial infarction. Control coronarogram revealed a subtotal occlusion of a covered $>2 \mathrm{~mm}$ side branch. At 6-month follow-up, two patients presented with recurrence of symptoms. Both showed a significant restenosis in the study stent, treated with balloon angioplasty. Table II shows the 6-month MACE in the intention-to-treat population and the per-protocol population.
TABLE II. 6-Month Clinical Follow-UP*

\begin{tabular}{|c|c|c|}
\hline & $\begin{array}{c}\text { Intention-to-treat set, } \\
\mathrm{n}=71\end{array}$ & $\begin{array}{c}\text { Per-Protocol set } \\
n=60\end{array}$ \\
\hline & \multicolumn{2}{|c|}{$\mathrm{N}(\%)$} \\
\hline Cardiac death & $1(1.4)$ & 0 \\
\hline Q-wave MI & 0 & 0 \\
\hline Non-Q-wave MI & $1(1.4)$ & 0 \\
\hline TLR & $2(2.8)$ & $2(3.3)$ \\
\hline CABG & 0 & 0 \\
\hline Total MACE & $4(5.6)$ & $2(3.3)$ \\
\hline
\end{tabular}

*MI, myocardial infarction; MACE, major adverse cardiac events; TLR, target lesion revascularazation; CABG, coronary artery bypass graft surgery.

\section{TABLE III. Angiographic Characteristics*}

n $(\%)$

Disease state

Single-vessel disease 38 (54)

Two-vessel disease $21(30)$

Three-vessel disease $10(14)$

Four-vessel disease 2 (3)

Vessels treated

RCA $22(31)$

LAD $29(41)$

LCx 14 (19)

First obtuse marginal 4 (6)

Ramus intermedius 2 (3)

Lesion classification $^{\mathrm{a}}$

A $15(21)$

B1 $34(48)$

B2 $19(27)$

C $3(4)$

Lesion length (mm) 9.3 (range, 3-15)

*Values are mean $\pm \mathrm{SD}$ or $\mathrm{n}(\%)$. LAD, left anterior descending artery; RCA, right coronary artery; LCx, left circumflex artery.

${ }^{a}$ According to AHA/ACC classification.

\section{Angiographic Results}

The angiographic characteristics of the intention-totreat stented coronary segments are presented in Table III. Forty-seven percent of the patients had at least twovessel disease; $33 \%$ had lesion type B2 or C. Thirty-three percent of stents were placed in right coronary artery, $39 \%$ in the left anterior descending artery (LAD), 20\% in the circumflex coronary artery. Quantitative coronary analyses of the intention-to-treat population and perprotocol population are summarized in Tables IV and V, respectively. In the intention-to-treat population, the mean lesion length was $9.91 \mathrm{~mm}$ with a range from 3 to $23.5 \mathrm{~mm}$. The mean reference diameter at baseline was $2.95 \pm 0.52 \mathrm{~mm}$. Minimal luminal diameter and percent diameter stenosis before the procedure were $1.02 \pm 0.35$ $\mathrm{mm}$ and $64.75 \% \pm 11.81 \%$, respectively. Late loss were 0.47 in lesion and 0.57 in the stent segment. Loss indexes 
TABLE IV. STRIDE QCA Data Safety Set $(n=71)^{\star}$

\begin{tabular}{lcc}
\hline & In-lesion & In-stent \\
\hline Pre-RVD (mm) & $2.95 \pm 0.52$ & \\
Pre-MLD (mm) & $1.03 \pm 0.35$ & \\
Pre-\% DS & $64.75 \pm 1.81$ & \\
Lesion length & $9.91(3-23.5)$ & \\
Post-RVD (mm) & $2.93 \pm 0.52$ & $2.99 \pm 0.42$ \\
Post-MLD (mm) & $2.47 \pm 0.46$ & $2.67 \pm 0.42$ \\
Post-\% DS & $15.47 \pm 7.17$ & $10.46 \pm 5.50$ \\
Follow-up RVD (mm) & $2.91 \pm 0.49$ & $2.87 \pm 0.51$ \\
Follow-up MLD (mm) & $1.98 \pm 0.60$ & $2.09 \pm 0.60$ \\
Follow-up \% DS & $32.30 \pm 14.80$ & $27.11 \pm 15.10$ \\
Acute gain (mm) & $1.45 \pm 0.52$ & $1.64 \pm 0.48$ \\
Late loss (mm) & $0.47 \pm 0.47$ & $0.57 \pm 0.48$ \\
Loss index & $0.34 \pm 0.36$ & $0.36 \pm 0.31$ \\
\hline
\end{tabular}

*RVD, reference vessel diameter; MLD, minimal luminal diameter; DS, diameter stenosis. $\mathrm{n}=64$ for the follow-up parameters.

TABLE V. STRIDE QCA Data Per-Protocol Set*

\begin{tabular}{lccc}
\hline & Pre & Post & 6 Months \\
\hline RVD (mm) & 2.95 & 2.93 & 2.93 \\
MLD (mm) & 1.02 & 2.49 & 2.02 \\
\% DS & 65 & 15 & 32 \\
Acute gain (mm) & & 1.47 & \\
Late loss (mm) & & & 0.45 \\
Loss index & & & 0.32 \\
Binary restenosis rate $(\%)$ & & & 13.3 \\
\hline
\end{tabular}

*RVD, reference vessel diameter; MLD, minimal luminal diameter; DS, diameter stenosis.

of in-lesion and in-stent segments were 0.34 and 0.36 , respectively.

In the per-protocol population, the mean lesion length was $9.5 \mathrm{~mm}$ with a range from 3 to $15 \mathrm{~mm}$. The mean reference diameter at baseline was $2.95 \pm 0.54 \mathrm{~mm}$. Minimal luminal diameter and percent diameter stenosis before the procedure were $1.02 \pm 0.37 \mathrm{~mm}$ and $64.95 \%$ $\pm 12.14 \%$, respectively. Late loss was 0.45 . Loss index was 0.32 . Binary restenosis rate was $13.3 \%$.

\section{Angiographic Results in Stable and Unstable Patients}

Subset QCA analyses of stable vs. unstable patients are shown in Table VI. At 6-month follow-up, the diameter stenosis of stable vs. unstable patients was $38.40 \% \pm$ $16 \%$ and $26.86 \% \pm 14 \%(P<0.05)$, respectively. The late loss was $0.60 \pm 0.55$ vs. $0.32 \pm 0.39 \mathrm{~mm}(P<$ $0.03)$, respectively.

\section{DISCUSSION}

This multicenter phase 2 trial shows that it is feasible to load a BiodivYsio Matrix Lo stent with dexamethasone and to deliver the stent safely at the target lesion
TABLE VI. STRIDE QCA Data of Stable Angina vs. Unstable Angina*

\begin{tabular}{lccc}
\hline & Stable angina & Unstable angina & $P$ \\
\hline Pre-RVD (mm) & $2.81 \pm 0.49$ & $2.90 \pm 0.45$ & NS \\
Follow-up RVD (mm) & $2.87 \pm 0.52$ & $2.92 \pm 0.47$ & NS \\
Pre-MLD (mm) & $1.06 \pm 0.28$ & $1.01 \pm 0.31$ & NS \\
Follow-up MLD (mm) & $1.80 \pm 0.70$ & $2.14 \pm 0.51$ & NS \\
Pre-\% DS & $61.64 \pm 11$ & $64.96 \pm 11$ & NS \\
Follow-up & $38.40 \pm 16$ & $26.86 \pm 14$ & 0.017 \\
Acute gain (mm) & $1.33 \pm 0.51$ & $1.45 \pm 0.52$ & NS \\
Late loss (mm) & $0.60 \pm 0.55$ & $0.32 \pm 0.39$ & NS (0.067) \\
Loss index & $0.46 \pm 0.37$ & $0.22 \pm 0.34$ & NS \\
\hline
\end{tabular}

*RVD, reference vessel diameter; MLD, minimal luminal diameter; DS, diameter stenosis.

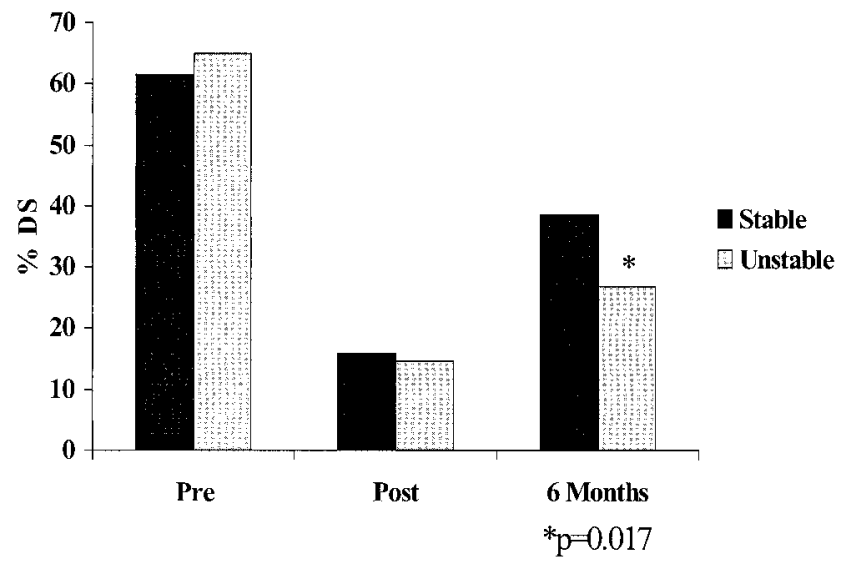

Fig. 1. Comparison of the \% diameter stenosis between the stable and unstable angina pectoris patient group. The unstable group included patients with unstable angina (new onset or changed pattern of angina over the previous 2 months and CCS class IV angina at presentation). The stable group included patients with stable angina (CCS class I, II, or III angina unchanged over $\geq 2$ months) or patients with a positive stress test.

site. Particularly with the dexamethasone solution that we used, the MACE rates at 6-month follow-up were acceptable and comparable with the data recently presented for RAVEL (MACE, 5.8\% [16]) and ELUTES (MACE, 11\% [17]); also, the late loss compared favorably to the findings of other studies evaluating bare noncoated [18,19], heparin-coated [20], and PC-coated BiodivYsio coronary stents [21]. This suggests that local delivery of dexamethasone by means of the BiodivYsio Matrix Lo stent may have a significant inhibitory effect on neointimal hyperplasia. This effect was more pronounced in the patient subgroup with unstable angina pectoris (Fig. 1). Unstable coronary plaques are known to contain important amounts of inflammatory cells, contributing to the vulnerability of the atherosclerotic plaque, causing significant morbidity. The binary reste- 
nosis rate $(13.3 \%)$ in this study was higher, however, than in recent presented studies with drug-eluting stents $[1,2]$. This might be due to the low dose of dexamethasone chosen in this study or because dexamethasone is less powerful in inhibiting neointimal hyperplasia compared to rapamycin or paclitaxel. Further studies using a higher dose of dexamethasone are under way to optimize this treatment modality.

\section{Study Limitations}

This study was an unblinded, nonrandomized pilot study without a control group. It was performed in a small selected group of patients. A randomized dose finding trial is mandatory to confirm these results and to evaluate the optimal dose needed to optimize these results.

\section{CONCLUSIONS}

Implantation of a dexamethasone-loaded BiodivYsio Matrix Lo stent to treat de novo coronary lesions is feasible and safe. There was no increased incidence of subacute or late stent thrombosis, although no prolonged antiaggregation treatment was given in this study. Clinical event rate and clinically driven revascularization need were low. Late loss was significantly lower compared with similar studies with bare, heparin-coated and PC-coated stents and the very low rate in unstable patients is interesting. Confirmation of an improved outcome should be shown in a prospective randomized trial comparing the dexamethasone-loaded stent with a nonloaded stent.

\section{REFERENCES}

1. Sousa JE, Costa MA, Abizaid A, Abizaid AS, Feres F, Pinto IM, Seixas AC, Staico R, Mattos LA, Sousa AG, Falotico R, Jaeger J, Popma JJ, Serruys PW. Lack of neointimal proliferation after implantation of sirolimus-coated stents in human coronary arteries: a quantitative coronary angiography and three-dimensional intravascular ultrasound study. Circulation 2001;103:192-195.

2. Honda Y, Grube E, de La Fuente LM, Yock PG, Stertzer SH, Fitzgerald PJ. Novel drug-delivery stent; Intravascular ultrasound observations from the first human experience with the QP2-eluting polymer stent system. Circulation 2001;104:380-383.

3. Beck BC, Gordon JB, Alexander RW. Pharmacologic roles of heparin and glucocorticoids to prevent restenosis after coronary angioplasty. J Am Coll Cardiol 1991;17:111B-117B.

4. Villa AE, Guzman LA, Chen W, Golomb G, Levy RJ, Topol EJ. Local delivery of dexamethasone for the prevention of neointimal proliferation in a rat model of balloon angioplasty. J Clin Invest 1994;93:1243-1249.

5. Lincoff AM, Furst JG, Ellis SG, Tuch RJ, Topol EJ. Sustained local delivery of dexamethasone by a novel intravascular eluting stent to prevent restenosis in the porcine coronary injury model. J Am Coll Cardiol 1997;29:808-816.
6. van der Giessen WJ, Lincoff AM, Schwartz RS, van Beusekom HM, Serruys PW, Holmes DR Jr, Ellis SG, Topol EJ. Marked inflammatory sequelae to implantation of biodegradeable and nonbiodegradeable polymers in porcine coronary arteries. Circulation 1996;94:1690-1697.

7. Campbell EJ, O’Byrne V, Stratford PW, Quirk I, Vick TA, Wiles MC, Yianni YP. Biocompatible surface using methacryloylphosphosphorylcholine laurylmethacrylate copolymer. ASAIO J 1994; 40:M853-M857.

8. Veil KR, Chronos NAF, Palmer SJ, Yianni J, Taylor A, Campbell E, Cippola GD Robinson KA. Phosphorylcholine: a biocompatible coating for coronary angioplasty devices. Circulation 1995;92: I489.

9. Galli M, Bartorelli A, Bedogni F, DeCesare N, Klugmann S, Maiello L, Miccoli F, Moccetti T, Onofri M, Paolillo V, Pirisi R, Presbitero P, Sganzerla P, Viecca M, Zerboni S, Lanteri G. Italian BiodiviYsio open registry (BiodiviYsio PC-coated stent): study of clinical outcomes of a PC-coated coronary stent. J Invas Cardiol 2000;12:452-458.

10. Zheng H, Barragan P, Corcos T, Simeoni JB, Favereau X, Roquebert PO, Guerin Y, Sainsous J. Clinical experience with a new biocompatible phosphorylcholine-coated coronary stent. J Invas Cardiol 1999;11:608-614.

11. De Scheerder, I, Huang Y. Anti-inflammatory approach for restenosis. In: Rothman MT, editor. Local drug delivery: state of art restenosis. London: ReMedica Books; 2001. p 13-31.

12. Lewis AL, Vick, TA, Collias AMC, Hughes LG, Palmer RR, Leppard SW, Furze JD, Taylor AS, Stratford PW. Phosphorylcholine-based polymer coatings for stent drug delivery. J Mater Sci Mater Med 2001;12:865-870.

13. Lewis AL, Vick TA. Site-specific drug delivery from coronary stents. Drug Delivery Syst Sci 2001;1:65-71.

14. Tang Y, Lu JR, Lewis AL, Vick TA, Stratford PW. Swelling of zwitterionic polymer filmscharacterized by spectroscopic ellipsometry. Macromolecules 2001;34:8768-8776.

15. Popma JJ, Basshore TM. Qualitative and quantitative angiography. In: Topol EJ, ed. Textbook of interventional cardiology, 2nd ed. Philadelphia: W.B. Saunders; 1994. p 1052-1068.

16. Morice MC, Serruys PW, Sousa JE, Fajadet J, Ban Hayashi E, Perin M, Colombo A, Schuler G, Barragan P, Guagliumi G, Molnar F, Falotico R. A randomized comparison of a sirolimuseluting stent with a standard stent for coronary revascularization. N Engl J Med 2002;346:1773-1780.

17. Gershlick A, De Scheerder I, for ELUTES investigators. Longterm follow-up in the ELUTES clinical study. Am J Cardiol 2002;90(Suppl 6A):1H.

18. Serruys PW, de Jaegere P, Kiemeneij F, Macaya C, Rutsch W, Heyndrickx G, Emanuelsson H, Marco J, Legrand V, Materne P, Belardi J, Sigwart U, Colombo A, Goy JJ, van den Heuvel P, Delcan J, Morel MA, for the BENESTENT study group. A comparison of balloon-expandable stent implantation with balloon angioplasty in patients with coronary artery disease. N Engl J Med 1994;331:489-495.

19. Fischman DL, Leon MB, Baim DS, Schatz RA, Savage MP, Penn I, Detre K, Veltri L, Ricci D, Nobuyoshi M, Cleman M, Heuser H, Almond D, Teirstein PS, Fish RD, Colombo A, Brinker J, Moses J, Shaknovich A, Hirshfeld J, Bailey S, Ellis S, Rake R, Goldberg $\mathrm{S}$, for the Stent Restenosis Study investigators. A randomized comparison of coronary-stent placement and balloon angioplasty in the treatment of coronary artery disease. N Engl J Med 1994; $331: 496-501$. 
20. Serruys PW, van Hout B, Bonnier H, Legrand V, Garcia E, Macaya C, Sousa E, van der Giessen W, Colombo A, SeabraGomes R, Kiemeneij F, Ruygrok P, Ormiston J, Emanuelsson H, Fajadet J, Haude M, Klugmann S, Morel MA. Randomised comparison of implantation of heparin-coated stent with balloon angioplasty in selected patients with coronary artery disease (Benestent II). Lancet 1998;352:673-681.

21. Boland JL, Corbeij HAM, van der Giessen W, Seabra-Gomes R, Suryapranata H, Wijns W, Hanet C, Suttorp MJ, Buller C, Bonnier JJRM, Colombo A, van Birgelen C, Pieper M, Mangioni JA, Londero H, Carere RG, Hamm CW, Bonan R, Bartorelli A, Kyriakides ZS, Chauhan A, Rothman M, Grinfeld L, Oosterwijk C, Serruys PW, Cumberland DC. Multicenter evaluation of the phosphorylcholine coated BiodivYsio stent in short de novo coronary lesions: the SOPHOS study. Int J Cardiovasc Intervent 2000;3:215-225.

\section{APPENDIX}

Participating centers and investigators are CG St. Jean Brussel (M. Vandormael), AZ St. Jan Brugge (L. Missault), UZ Antwerp (C. Vrints), UZ Ghent (Y. Taeymans), UCL St. Luc (C. Hanet), CHU Sart Tilman (V. Legrand), CHU St. Pierre (J.L. Vandenbossche), and UZ Leuven (I. De Scheerder). 